\title{
INFLUENCE OF PARAMETERS OF RAILWAY TRACK CONSTRUCTION ON VERTICAL DYNAMIC INTERACTION VEHICLE/TRACK
}

By analysing the dynamic interaction between the railway vehicle and the track we are able to explain complex interactive phenomena that are particularly important in the case of higher and high speed of a moving rail vehicle on railway track.The paper focuses on the solution of the above mentioned problem with the help of numerical computer simulations. The important step on the way to create a respective simulation model is setting objective entry parameters of railway track as well as taking its imperfections into consideration. These imperfections significantly influence the results of dynamic interaction. Out of the considered track imperfections, we particularly solve deformation resistance inhomogeneity of track grid subgrade and vertical irregularities of rail belt.

\section{Introduction}

The railway infrastructure presents a strategical component of Slovak transport infrastructure from the point of view of securing continuous national and transit transport within the European Union.The most important transit rail tracks crossing the Slovak Republic are defined according to international conventions $A G C$ (1985) and AGTC (1993). These rail tracks have to fulfill Technical Interoperability Specifications (TSI). From the point of view of rail track construction, for the chosen track corridors it means that there has to be enabled reaching the operating speed $160 \mathrm{kmh}-1$ at the maximal axle weight 22.5 tons (loading capacity class $D 4 U I C$ ) in the whole longest possible rail localities. The rail track, as it is a significantly inhomogeneous construction, is a subject to influence of operation and climatic factors. Together with the passing time they result in geometric and material deformities by wearing of all the components of track grid and particularly construction layers of sleeper subgrade. By the influence of load increase on modernised rail localities, these geometrical and material degradations are more obvious as a consequence of higher force effects. Recognition and subsequent development prediction of these degradations are conditioned by perfect recognition of acting force effects of rail vehicles. Particularly in the case of high and higher speed, the dynamic interaction force effects are significantly noticeable. They influence the durability and reliability of rail construction in a crucial way and therefore they ought to be expressly considered in the process of construction design and dimensioning.

Lately, the computer simulation of dynamic interaction of complex mechanical system vehicle/ track has had significant influ- ence on the knowledge of structure of interactive wheel forces. In the ties of a mechanical system defined in such a way, dynamic interactive forces are produced whose character and size are necessary to be precisely specified. In this paper we focus not only on the determination of a suitable model for simulation of dynamic interaction vehicle/track, but also on setting objective track parameters that will form a basis for wide application in various application simulations. There is also reference to the present deficiencies in the process of design of rail track construction and there are implied solution possibilities in the form of new approaches to rail track construction dimensioning. They are a result of theoretical simulation analyses that we suppose to verify by experimental measurements in near future in the new laboratory of Faculty of Civil Engineering in Vel'ký Diel campus. In this laboratory there will also be located a dynamic pulsator for cyclical loading tests.

\section{Basic Model Characteristics of Track and Rail vehicle in the $S R$}

The theoretical solution of mechanical problems of rail tracks is carried out on a certain physical model that should sufficiently characterize the basic properties of a mechanical system being solved. These basic properties should also be determinant for the correct interpretation of behaviour of the construction in the given model and they should keep the geometrical similarity with the real construction. The parameters that characterize the construction should at the same time correlate with the parameters that could be determined by standard or other simple diagnostic methods.

\footnotetext{
* Libor Izvolt, Jan Kardos

Faculty of Civil Engineering, University of Zilina, E-mail: libor.izvolt@fstav.uniza.sk
} 


\subsection{Rail Vehicle}

To make a suitable physical model of a train unit it is necessary to use a model of such train unit that is determinant from the point of view of size of effective dynamic forces and the most sensitive from the point of view of feedback e.g. in the form of comfort by travelling. In the conditions of $\check{Z} S R$, these are mainly passenger train units EPJ 671 that were purchased in 2010 for the operation in corridor tracks with maximum speed up to $160 \mathrm{kmh}^{-1}$. The mentioned train unit consists of electrical double decker rail car EPV 671, double decker trailer car $P V V 071$ and double decker managing car $P R V$ 971. From the point of view of possible activity of dynamic force effects on the rail track, the car EPV 671 is determinant. Its weight according to Tab. 1 is 87.5 tons, which presents static wheel loading $107.3 \mathrm{kN}$ for the four-axle symetrical bogie.

To evaluate the dynamic effects of rail vehicles on the construction of rail track, the symetry of vehicle/track system is used. This task is practically always solved as a plane problem i.e. applied load of one rail belt and the respective plane interactive model of vehicle/track system are considered (analyzed in detail in chapter 4). In the process of transformation of solution of a given system from three-dimensional to plane one, it is desirable to take several factors into account. They influence the results of solution and are often neglected in plane interactive tasks. The basic factors influencing the force symetry of rail car system are particularly real irregular crosswise mass distribution in the rail cars, influence of centrifugal force in arc with unbalanced crosswise acceleration, change of rail nivelity, transition to superelevation, etc. In Tab. 2 there is a summary of maximum effects of increase of wheel force for the car EPV 671.

We have to be aware of the fact that the maximum loading capacity of a train unit is not always utilised and the occurence of increase of wheel force from Tab. 2 even in the case of reaching high values is only in specific short track localities, possibly in the case of specific climatic influences. Therefore the synergic coaction of these effects is rare and for the objective analysis of dynamic interaction vehicle/track it is enough to consider the standard wheel

Basic parameters of unit EPJ 671

Tab. 1

\begin{tabular}{|c|c|c|c|}
\hline \multirow{2}{*}{ Parameter } & \multicolumn{3}{|c|}{ EPJ 671} \\
\hline & EPV 671 & PVV 071 & PRV 971 \\
\hline Maximum operational speed & \multicolumn{3}{|c|}{$V=160 \mathrm{~km} \cdot \mathrm{h}^{-1}=44.45 \mathrm{~m} \cdot \mathrm{s}^{-1}$} \\
\hline Length of car along the buffer plane & \multicolumn{3}{|c|}{$3 \times 26,400 \mathrm{~mm}$} \\
\hline Height of car from the rail surface & \multicolumn{3}{|c|}{$4,635 \mathrm{~mm}$} \\
\hline Width of car & \multicolumn{3}{|c|}{$2,820 \mathrm{~mm}$} \\
\hline Arrangement of bogies & $B o^{\prime} B o^{\prime}$ & $2^{\prime} 2^{\prime}$ & $2^{\prime} 2^{\prime}$ \\
\hline Gauge & \multicolumn{3}{|c|}{$1,435 \mathrm{~mm}$} \\
\hline Wheel base of bogie & $L_{W}=2,600 \mathrm{~mm}$ & $L_{W}=2,400 \mathrm{~mm}$ & $L_{W}=2,400 \mathrm{~mm}$ \\
\hline Distance of centre of bogies ' rotation & $L_{B}=19,000 \mathrm{~mm}$ & $L_{B}=19,000 \mathrm{~mm}$ & $L_{B}=19,000 \mathrm{~mm}$ \\
\hline Distance of external bogies & $21,600 \mathrm{~mm}$ & $21,600 \mathrm{~mm}$ & $21,600 \mathrm{~mm}$ \\
\hline Number of sitting/standing passengers & $61 / 67$ & $134 / 134$ & $106 / 134$ \\
\hline Weight of empty car & $74 \mathrm{t}$ & $45.3 \mathrm{t}$ & $47.3 \mathrm{t}$ \\
\hline Maximum car weight at full loading capacity & $87.5 \mathrm{t}$ & $69.5 \mathrm{t}$ & $69.5 \mathrm{t}$ \\
\hline Maximum bogie weight & $22 \mathrm{t}$ & $18 \mathrm{t}$ & $18 \mathrm{t}$ \\
\hline
\end{tabular}

Growth of maximum possible increases of wheel force for EPV 671

Tab. 2

\begin{tabular}{|l|c|c|}
\hline \multicolumn{1}{|c|}{ Effect of increase of wheel force as a result of... } & $\begin{array}{c}\text { Increase of wheel force } \Delta P_{k} \\
\text { at maximum loading EPV 671 }\end{array}$ & $\begin{array}{c}\text { Maximum size of wheel force } \\
P_{k} \text { with increase } \Delta P_{k}\end{array}$ \\
\hline $\begin{array}{l}\text { transition to the superelevation of maximum inclination 1:1,600 and 1:1,280 accord- } \\
\text { ing to STN 73 6360 [1] for RP4 }\end{array}$ & $0.3 \mathrm{kN} / 0.5 \mathrm{kN}$ & $107.6 \mathrm{kN} / 107.8 \mathrm{kN}$ \\
\hline $\begin{array}{l}\text { maximum side wind according to III. and IV. wind area in accordance with } \\
\text { STN 73 0035 at average centre height according to STN P ENV 13803-1 [2] }\end{array}$ & $12.0 \mathrm{kN} / 15.5 \mathrm{kN}$ & $119.3 \mathrm{kN} / 122.8 \mathrm{kN}$ \\
\hline $\begin{array}{l}\text { centrifugal force in arc with maximum irregular acceleration 0.65 ms } \\
0.85 \mathrm{~ms}^{-2} \text { according to STN 73 6360 [1] }\end{array}$ & $9.5 \mathrm{kN} / 12.0 \mathrm{kN}$ & $117.1 \mathrm{kN} / 119.3 \mathrm{kN}$ \\
\hline $\begin{array}{l}\text { change of the rail nivelity (taper to the elevation arc) with vertical acceleration } \\
0.22 \mathrm{~ms}^{-2} \text { and 0.31 ms }\end{array}$ according to STN P ENV 13803-1 [2] & $2.5 \mathrm{kN} / 3.5 \mathrm{kN}$ & $109.8 \mathrm{kN} / 112.3 \mathrm{kN}$ \\
\hline \begin{tabular}{l} 
irregular mass distribution in the rail car at the heigth of 5\% and 7\% (estimated) \\
\hline
\end{tabular} & $5.5 \mathrm{kN} / 7.7 \mathrm{kN}$ & $112.8 \mathrm{kN} / 115.0 \mathrm{kN}$ \\
\hline
\end{tabular}


force $P_{k}=112.5 \mathrm{kN}$. This force is $5 \%$ bigger compared with maximum wheel force of the considered car EPV 671. This difference will sufficiently cover wheel force fluctuations concerning possible effects of wheel force increase and their probable occurence. In this case there should not be considered static wheel force but quasi-static wheel force that takes the motion of the vehicle and the wind influence into account but does not cause crosswise system vibration (2D model).

\subsection{Rail Track Construction}

The rail superstructure on already modernised corridor tracks of ZSR is formed by the system that consists of rails $60 \mathrm{El}$ on concrete sleepers with inclination of upper areas 1:40 (classic superstructure), non-plate flexible rail fastening system VOSSLOH Skl14, with sleeper spacing of type $U I C(600 \mathrm{~mm})$. With the rail of shape $60 \mathrm{El}$ there is most often used typal ferroconcrete sleeper $B P 3$ or $B 91 S / 1$. A certificate has been issued for using this type in ZSR Between the rail and sleeper there is placed an elastic rubber pad, most frequently WU7 or WS7. The concrete sleepers are embedded in railway ballast of gravel of fraction $31.5 / 63 \mathrm{~mm}$, while the width of railway ballast under the lower area of sleepers is $350 \mathrm{~mm}$. The subbase has an unstable width depending on the initial deformation resistance of subgrade. According to TNZ 736312 [3] there is required an equivalent value of static deformation module on the level of subgrade surface $30 \mathrm{MPa}$ and on the level of surface of railway substructure $50 \mathrm{MPa}$. By calculating in accordance with dimensioning methodology SOJUZDORNII it is possible to determine the static deformation module on the level of lower area of sleepers to $95 \mathrm{MPa}$. Reaching the normative values depends on season, technology of construction manufacturing, and on the state of compaction of construction layers by operation [4]. The summary of basic parameters of a modernised track (state of new building) is given in Tab. 3 .

The size of pad stiffness coefficient $K_{p}$ and attenuation $C_{p}$, (parameters stated according to STN EN 13146-3 and STN 131469), depend on the type of pad material (HDPE, rubber, rubbercork), width, environment temperature, its age (i.e. entire amount and size of loading cycles applied to the pad), as well as contact force of rail fastening. Because of this, values of these parameters are given in wide application interval in various studies $\left(K_{P}=60 \times 10^{3}\right.$ to $1000 \times 10^{3} \mathrm{kNm}^{-1}$ and $C_{P}=40$ to $120 \mathrm{kNsm}^{-1}$ ). However, for dynamic evaluation of rail track construction in the model there should be used values of the pad stiffness set by dynamic measurement. According to STN EN 13481-2, in case of using concrete sleepers in the main track they should reach values 100 to $200 \mathrm{MNm}^{-1}$. In Tab. 3 there are used the average parameter values for the pad leading from comparison of several studies.

The biggest deficiencies in determining parameters given in Tab. 3 are in stating the values of the module elasticity, stiffness, and attentuation of construction layers of sleeper subgrade. The equivalent modules of elasticity of a given construction layer of subgrade defined in $T a b .3$ were determined from minimum required values of deformation modules, on the basis of analogy of deter- mination of equivalent elasticity modules with the static loading test according to STN 736190 [5] (the relation leads from the definition of Bousinesque's elastic half-space). The elastic deformations for the calculation of elasticity modules were considered from the second lightening branch, in the interval of tension according to anticipated tension range in a given construction layer (geostatic tension to the addition of geostatic and incremental tension). This approach to determination of equivalent elasticity modules takes into account the theoretical principles of Hook's law (the dependence of tension and deformation in a small interval is linear and this interval is also the interval of real operation of tension in a given construction layer). The indicative elasticity intervals are on the level of lower area of sleeper in the interval $<0.01$ to 0.30 $\mathrm{MPa}>$, on the level of surface of rail substructure for the width of railway ballast $0.35 \mathrm{~m}$ in the interval $<0.02$ to $0.30 \mathrm{MPa}>$ and on the level of subgrade surface for the width of subbase $0.30 \mathrm{~m}$ in the interval $<0.03$ to $0.05 \mathrm{MPa}>$. The problem of using loading diagrams from the static loading test according to regulation $\check{Z} S R$ $S 4$ [6] is the fact that the most frequently used tension interval under loading board $<0$ to $0.20 \mathrm{MPa}>$ on the level of subgrade surface with the deformation module $30 \mathrm{MPa}$ is significantly overestimated concerning the interval of operation tension in this depth. Because of this, in Tab. 3 there are used entire tension intervals from the average static loading test for the required level of deformation module $30 \mathrm{MPa}, 50 \mathrm{MPa}$ and $95 \mathrm{MPa}$ to calculate elasticity modules. From an elasticity module deduced in such a way it is possible to determine the static stiffness of subbase (elastic constante) from the following theoretical relation [7]:

$$
K_{i}=\frac{E_{i}}{\left(1-v_{i}^{2}\right)} \cdot 2 r \quad\left(\mathrm{kNm}^{-1}\right)
$$

where:

$E_{i} \quad$ - is elasticity module in strain of i-th construction layer material,

$r_{i} \quad$-is radius of loading board $(0.15 \mathrm{~m})$,

$v_{i} \quad$-is Poisson's constant of i-th construction layer material.

The theoretical relation does not count with the fact that the elasticity module, used in the relation, is determined from the second lightening branch according to STN 736190 [5], while the coefficient of compressibility (elastic constant) defines the dependence of loading and deformation from steady hysteresis curve (nth load branch) without permanent deformations (linear elastic constant).The compressibility coefficients should also be determined in the interval of assumed tension state for the given construction layer. The required increase of value of elastic constant from relation (1) as a result of elimination of plastic transformation is approx. $20 \%$ and the elastic constant parameters stated in Tab. 3 are also changed according to this value.

In the construction layers of sleeper subgrade, damping takes place as a result of internal friction of particles (dissipation).The diagnostics of attenuation characteristics of sleeper subgrade construction has not been stated yet, while these parameters are vital for creation of a respective simulation model for determining the dynamic response vehicle/track. For damping of oscillation of mechanical system we introduce a supposition that the resistance 
Summary of basic track parameters for modeling vertical dynamic interaction

\begin{tabular}{|c|c|c|c|}
\hline \multicolumn{3}{|c|}{ Parameter description } & Parameter value \\
\hline \multirow{11}{*}{ 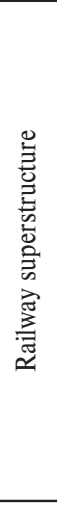 } & \multicolumn{2}{|c|}{ Young's model of elasticity in strain of rail $60 \mathrm{E} 1$} & $E=E_{R}=2.07 \times 10^{11} \mathrm{Nm}^{-2}$ \\
\hline & \multicolumn{2}{|c|}{ Cross-sectional moment of inertia of rail $60 \mathrm{E} 1$} & $I_{y}=I_{R}=3.055 \times 10^{-5} \mathrm{~m}^{4}$ \\
\hline & \multicolumn{2}{|c|}{ Flexural stiffness of rail in the vertical direction $60 \mathrm{E} 1$} & $E I_{y}=6.3239 \times 10^{3} \mathrm{kNm}^{3}$ \\
\hline & \multicolumn{2}{|c|}{ Longitudinal weight of rail $60 \mathrm{E} 1$} & $M_{R}=60.34 \mathrm{kgm}^{-1}$ \\
\hline & \multicolumn{2}{|r|}{ Hertz's contact stiffness wheel/rail (better to consider a nonlinear one in the calculation) } & $K_{H}=2,4.105 \mathrm{kNm}^{-1}$ \\
\hline & \multicolumn{2}{|c|}{ Cross-sectional rail area $60 \mathrm{E} 1$} & $A_{y}=A_{R}=76.86 \times 10^{-4} \mathrm{~m}^{2}$ \\
\hline & \multicolumn{2}{|c|}{ Poisson's constant of rail material $60 \mathrm{E} 1$} & $v_{R}=0.27$ \\
\hline & \multicolumn{2}{|c|}{ Volume weight of rail $60 \mathrm{E} 1$} & $\rho_{R}=7,850 \mathrm{kgm}^{-3}$ \\
\hline & \multicolumn{2}{|c|}{ Weight of half-sleeper BP 91/S1 } & $M_{S}=304 / 2 \mathrm{~kg}=152 \mathrm{~kg}$ \\
\hline & \multicolumn{2}{|c|}{ Pad stiffness coefficient WU 7} & $K_{P}=120 \times 10^{3} \mathrm{kNm}^{-1}$ \\
\hline & \multicolumn{2}{|c|}{ Pad attenuation coefficient WU 7} & $C_{P}=50 \mathrm{kNsm}^{-1}$ \\
\hline \multirow{23}{*}{ 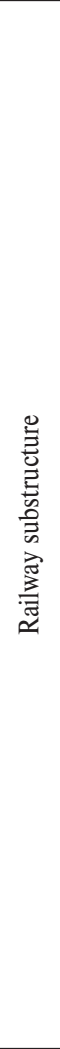 } & \multirow{7}{*}{ 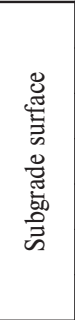 } & Minimum equivalent deformation module according to TNŽ 736312 [3] & $E_{e k v, 1}=30 \mathrm{MPa}$ \\
\hline & & Equivalent elasticity module according to STN 736390 & $E_{1}=35 \mathrm{MPa}$ \\
\hline & & Poisson's constant for soil S1 to S5 with reachable $E_{e k v, 1}=30 \mathrm{MPa}$ & $v_{1}=0.35$ \\
\hline & & Typical value of volume weight at standard rate of compaction & $\rho_{1}=1,850 \mathrm{kgm}^{-3}$ \\
\hline & & Equivalent co-oscillating mass for plane model & $M_{1}=430 \mathrm{~kg}$ \\
\hline & & Coeff. of subbase stiffness determined from the curve of static load test according to (1) & $K_{1}=15 \times 10^{3} \mathrm{kNm}^{-1}$ \\
\hline & & Coefficient of subbase attenuation determined according to relation (2) & $C_{1}=85 \mathrm{kNsm}^{-1}$ \\
\hline & \multirow{7}{*}{ 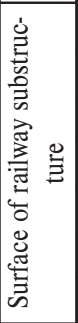 } & Minimum equivalent deformation module according to TNŽ 736312 [3] & $E_{d e f, 2}=50 \mathrm{MPa}$ \\
\hline & & Equivalent elasticity module according to STN 736390 & $E_{2}=E F=60 \mathrm{MPa}$ \\
\hline & & Poisson's constant for crushed stone $\mathrm{S} 1$ to $\mathrm{S} 5$ with reachable $E_{e k v, 2}=50 \mathrm{MPa}$ & $v_{2}=v_{F}=0.25$ \\
\hline & & Typical value of volume weight at standard rate of compaction & $\rho_{2}=2,050 \mathrm{kgm}^{-3}$ \\
\hline & & Equivalent co-oscillating mass for plane model & $M_{2}=M_{F}=480 \mathrm{~kg}$ \\
\hline & & Coeff. of subbase stiffness determined from the curve of static loading test according to (1) & $K_{2}=K_{F}=23 \times 10^{3} \mathrm{kNm}^{-1}$ \\
\hline & & Coefficient of subbase attenuation determined according to relation (2) & $C_{2}=C_{F}=110 \mathrm{kNsm}^{-1}$ \\
\hline & \multirow{9}{*}{ 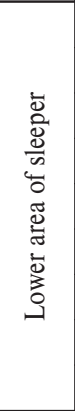 } & Calculated equivalent deformation module according to TNŽ 736312 [3] & $E_{d e f, 3}=95 \mathrm{MPa}$ \\
\hline & & Equivalent elasticity module according to STN 736390 & $E_{3}=E_{B}=110 \mathrm{MPa}$ \\
\hline & & Poisson's constant for crushed stone (fr. $31,5 / 63 \mathrm{~mm}$ ) with reachable $E_{e k v, 3}=95 \mathrm{MPa}$ & $v_{3}=v_{B}=0.25$ \\
\hline & & Typical value of volume weight at standard rate of compaction & $\rho 3=2,400 \mathrm{kgm}^{-3}$ \\
\hline & & Equivalent co-oscillating mass for a plane model & $M_{3}=M_{B}=750 \mathrm{~kg}$ \\
\hline & & Coeff. of subbase stiffness determined from the curve of static load test according to (1) & $K_{3}=K_{B}=42 \times 10^{3} \mathrm{kNm}^{-1}$ \\
\hline & & Subbase attenuation coefficient determined according to relation (2) & $C_{3}=C_{B}=170 \mathrm{kNsm}^{-1}$ \\
\hline & & Coefficient of subbase stiffness in slide & $K_{3 h}=K_{W}=40 \times 10^{3} \mathrm{kNm}^{-1}$ \\
\hline & & Coefficient of subbase attenuation in slide & $C_{3 h}=C_{W}=80 \mathrm{kNsm}^{-1}$ \\
\hline
\end{tabular}

of system movement is proportional to the speed of movement (linear possibly viscous attenuation). According to [8] it is possible to use the following theoretical relation to calculate the coefficient of attenuation:

$$
C_{i}=\sqrt{\frac{E_{i} \cdot \rho_{i}}{1-v_{i}^{2}}}\left(\mathrm{kNsm}^{-1}\right)
$$

where:

$E_{i} \quad$-is elasticity module in strain of i-th construction layer material,

$\rho_{i} \quad$-is volume weight of i-th construction layer material,

$v_{i} \quad$-is Poisson's constant of i-th construction layer material.
All the values of elasticity and deformation modules, Poisson's constants, coefficients of stiffness and damping given in Tab. 3 are stated by static loading. The dynamic characteristics of soil of sleeper subgrade are necessary to be found out by experimental measurements e.g. via cyclic loading tests with different frequency composition and deviation (dynamic pulsator). The analysis of dynamic soil characteristics is carried out e.g. in [9]. From this one we can conclude that all the dynamic quantities have higher values as a result of shorter and cyclically active force and in this way smaller deformation (at frequency 5 to $10 \mathrm{~Hz}$ dynamic elasticity modules and Poisson's constants are bigger in 10 to $35 \%$ when compared to static ones). By assembling a model for simulation of dynamic 
interaction vehicle/track with consideration of dynamic characteristics of entry parameters, there is obvious higher model stiffness of train construction and in this way also possibly higher values of dynamic interactive forces. There is a recent plan to observe the dynamic characteristics of common materials constituting sleeper subgrade in accordance with valid norms and regulations with the help of newly-built dynamic pulsator of the University of Žilina. These results will significantly help specify the entry parameters in order to create a relevant dynamic interactive track model.

\section{Mathematical Model of Vertical Dynamic Interaction Vehicle/Track}

The method of mathematical modeling of the vehicle and rail track is used for understanding the complicated dynamic interactions between vehicle and track. The solution of dynamic response of construction of rail and vehicle as a plane task gives in the case of correct formulation and setting entry parameters almost the same results as solutions of complex three-dimensional tasks. To observe the vertical dynamic interactions of wheel and rail track it is thus enough to use the plane calculation model of vehicle and track.

\subsection{Calculation Model of Rail Vehicle}

The calculation model of rail vehicle is usually considered as a 2-level plane model with sprung bogies and car body. In the design of the mathematical model that serves to study dynamic behaviour of vehicles, it is usually supposed that the system com- ponents are solid, and the elastic deformations and vibrations are ignored. All the relations between wheel and bogie and bogie and car body (viscous dampers, spring elements) are considered linear. A plane vehicle model, made in this way, enables to model the influence of vertical movement of sprung mass (heavy effect) and the influence of swinging of sprung mass in longitudinal direction (pitch effect). The influence of inclination of sprung mass in crosswise direction (roll effect) on the formation of kinematic quantities of the model is not taken into consideration. However, it is included in quasi-static speculation of wheel force as in part 2.1. The contact of wheel and rail takes into account contact deformation on the basis of Hertz' theory, considering the contact stiffness $K_{H}$. The Hertz's theory assumes elastic deformations on the contact of wheel and rail depending on vertical interactive force and the way of contact of rail surface and wheel rim [10]. As a consequence, in the model it is necessary to consider the Hertz' contact stiffness as a function of vertical interactive force that has inconstant value (non-linear Hertz contact spring).To solve the equations of entire system with non-linear Hertz theory, it is suitable to use the iteration method to calculate $K_{H}$. in each time step. The example of interactive model of system vehicle/track that is sufficient to analyse the standard characteristics of dynamic interaction of rail car EPV 671 is demonstrated in Fig. 1. The vehicle model has 10 degrees of freedom. The bogie frame is connected to the wheels of unsprung mass through the primary springs of suspension and connected to the car body through secondary springs of suspension. The designed discreet calculation model has to respect geometrical and physical parameters of vehicle and track as well as the most important imperfections influencing dynamic interaction vehicle/ track (Tab. 1 and Tab. 3).

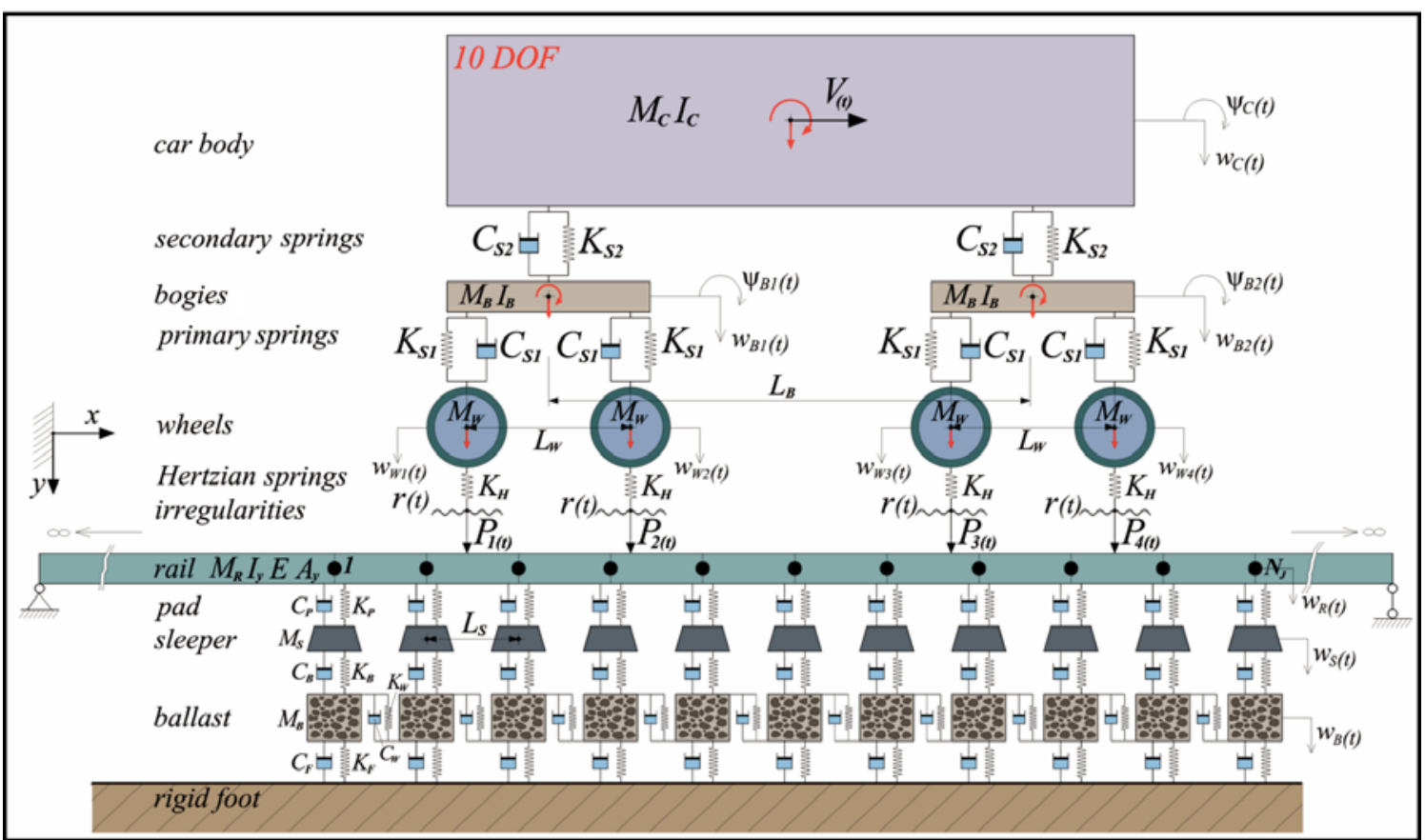

Fig. 1 Example of interactive model of system vehicle/track 


\subsection{Calculation Model of Track Construction}

The calculation model of rail track is considered as a plane model of one rail belt that is modelled by simple beam component (rail), solid support component (sleepers), connecting and damping components.The connecting components (ties)- rail/pad, pad/ sleeper, and sleeper/subgrade layers are double-nodal spring- damping components. The characteristics of these components could be set as either linear or non-linear characteristics, although in practical calculations they are solved as linear ones. The parameter values of these components should unequivocally be set in dynamic loading mode (see part 2.2) The rail is assumed as a homogenous beam with $N_{J}$ nodes and $N_{E}$ components. Each beam mode (rail structure) has two degrees of freedom. In the model we consider the effect of half-sleeper on viscous-elastic basis. The number of sleepers in model $N_{S}$ depends on the way of analysing the dynamic interaction. In the case of considering stochastic stiffness of beam and imperfection of rail geometry, it is more advantageous to consider a higher number of sleepers in the model (50 to100 sleepers). To model the subgrade unhomogeneity, it is better to use a multi-layer model consisting of railway ballast, subbase, possibly soil of subgrade surface. The model of sleeper subgrade contains additional gravel mass under each sleeper. The sleepers are connected through the spring and damper in skid $\left(K_{W}\right.$ and $\left.C_{W}\right)$. According to several well-known studies, with this type of model there could be gained better correlations between the calculated and measured responses. The model is usually limited in vertical direction on the level of subgrade surface (solid plane). To this there are connected spring-damping components with parameters of subbase $K_{F}, C_{F}$ (surface of railway substructure) according to $T a b$. 3. The main movement equations for discreet system with several degrees of freedom (dynamic balance equations) are composed according to a following relation [11]:

$$
[M]\{\ddot{w}\}+\left[C_{b}\right]\{\dot{w}\}+[K]\{w\}=\{P\}
$$

where:

$\{w(x, t)\}-$ is a vector of generalised shifts in nodal points of final components,

$[M] \quad$ - is a global matrix of system weight,

$\left[C_{b}\right] \quad$ - is a global matrix of system damping,

$[K] \quad$ - is a global matrix of system stiffness,

$\{P\} \quad$ - is external node load.

The components of shift vector $[w(x, t)\}$ undoubtedly determine the deformation state of track in any place of construction $x$ and in any time $t$. The shift vectors are primarily composed by unknown quantities, that serve to calculate the internal forces of construction and reactions within the system ties. The global matrices of weight, damping and stiffness of the system are generated from component matrices (connecting components and masses). The numerical time integration is applied to differential equations of dynamic balance. As a result, the movement of rail vehicle on the track is discretized and the equations of dynamic balance are fullfilled only in the final number of time moments. The length of integration step $\Delta t$ is usually chosen between 0.025 to $0.200 \mathrm{~ms}$ [11]. The actual interactive analysis of the vehicle moving on the track is based on the use of so-called topical position of the vehicle in a movable coordinate system. This involves automatic leaving out the sleeper and its ties on one side and addition of sleepers with ties on the second one. After the sleeper shift from the end to the beginning of the examined area, the update takes place - new system parameters are introduced to the matrix of stiffness and attenuation (in the case of stochastic model).This means that the dynamic calculation model works inversely.

\section{Software Systems for Solution of Dynamic Interaction Vehicle/Track}

The computer simulation of vertical dynamic interaction rail vehicle/track helps clarify complex interaction phemomena and at the same time evaluate the influence of chosen parameters on the quantities of dynamic response of rail track. The task formulated in such way cannot be effectively solved using conventional business numeric programe systems (FEAT, NEXIS, SCIA, ANSYS, ABAQUS, LUSAS, DIANA, ATENA, SOFISTIK, NASTRAN, ADINA, PLAXIS, COSMOS etc.), but has to use special calculation programmes that are individually programmed prevailingly for the purposes of calculation, most frequently in the programming languages $\mathrm{C}^{++}, \mathrm{FOR}$ TRAN, VISUAL BASIC or MATLAB. On this purpose several programmes were created, short overview of these is listed in $T a b$. 4. Most of them enables to take all the requirements defined in this paper into account.

\section{Conclusion}

The experimental measurements of dynamic interaction vehicle/ track realized in situ present the only way of verification of numeric results and also the only way of revealing objective reality. At the same time it is necessary to emphasize that carrying out of such experimental measurements in the rail track under operation is often limited by the possibility of sensor installation in one measured place only. In the case of placing the measuring devices on the car bogies we cannot reliably describe the rail track parameters that cause the given dynamic reaction [17]. Because of this, the computer simulations of dynamic interaction vehicle/track are really important.They enable us to analyse specific problems of dynamic interaction. From the parametric analysis of several programmes of dynamic interaction vehicle/track as well as from several studies carried out in this area we could conclude that the programmes in use are sensitive to the values of entry parameters of subgrade of rail track. The authors of several studies deal freely with the subgrade parameters as with variable quantity and they subsequently use these parameters to match them with simulation results so they would correlate with the results of experimental measurements or other simulations. The entry characteristics of rail track should be expressly defined on the basis of carried out diagnostic methods realized in real rail track construction possibly from limit standard values that are tolerable in operational conditions. The diagnostic methods of construction layers of sleeper subgrade should also consider dynamic mode of construction loading in the range of frequency and tension that will be active in the given construction 
Overview of programmes for direct solution of dynamic interaction vehicle/track

Tab. 4

\begin{tabular}{|c|c|c|}
\hline Name of programme & Responsible author & Institution where programme was developed \\
\hline DIFF [12] & Dr. Jens Nielsen & centre of excellence in Railway Mechanics at Chalmers University of Technology, Sweden \\
\hline NUCARS [12] & Dr. Nick Wilson & American Association of Railroads (AAR), Transportation Technology Centre Inc. (TTCI) \\
\hline 3DWTSD [12] & Dr. Yan Quan Sun & Central Queensland University, Australia \\
\hline TRACK [12] & Dr. Stuart Grassie & Stuart Grassie Engineering Solutions, Cambridge University, United Kingdom \\
\hline DTRACK [13] & Dr. Zhengi Cai & DynTrack Systems, USA and Queen's University, Canada \\
\hline DARTS [14] & Prof. Coenraad Esveld & Esveld Consulting Services, Delft University of Technology, Netherlands \\
\hline SUBTTI [12] & Dr. Ulf Gerstberger & Technical University Berlin, Germany \\
\hline VICT [12] & Prof. Wanhimng Zhai & Southwest Jiaotong University, China \\
\hline RAIL [14] & Dr. Valéri Markine & Delft University, Netherlands \\
\hline DATI [15] & Dr. Jabbar Ali Zakeri & University of Science and Technology, Iran and Beijing Jiaotong University, China \\
\hline IIT [12] & Dr. G. Kumuran & Indian Institute of Technology, India \\
\hline VIA [13] & Dr. Buch A. Roda & University of Valencia, Spain \\
\hline RTRI [12] & Dr. Makoto Ishida & Railway Technical Research Institute, Japan \\
\hline TRADYS [15] & Dr. Miwa Masahiro & Central Japan Railway Company and Tokyo University of Technology \\
\hline DIASTARS [16] & Dr. Makoto Tanabe & Kanagawa Institute of Technology and Railway Technical Research Institute, Japan \\
\hline C32/Interakcia [11] & Prof. Milan Moravcik & University of Zilina, Slovakia \\
\hline
\end{tabular}

layer during operation. To determine the dynamic parameters in the given construction layer, the simulation of dynamic interaction vehicle/track is notably applicable. By advancing iteration of values of operational frequencies and tensions determined from computer simulations, and values of dynamic characteristics of materials in individual construction layers determined e.g. by experimental measurements with dynamic pulsator, it will be possible to design a mathematical model with entry parameters in accordance with real operational conditions.From the simulation results, it will be subsequently possible to verify the criteria for geometrical position and rail arrangement in synergy with criteria for deformation resistance of subgrade. It can also be assumed that it will be necessary to define the requirements of reaching a certain homogeneity level of deformation resistance of subgrade, possibly to set such technological methods of manufacturing the construction layers of subgrade (e.g. by intelligent compaction cylinders [18]) that will secure the required and verifiable level of subgrade homogeneity. The important part of considering these and defining new criteria is applying stochastic parameters of track and vehicle in models. These could be stiffness of rail fastening, sleeper spacing, stiffness and attenuation of subgrade, regular and irregular imperfection of rail geometry, wheel imperfection, floating sleepers, unstable speed of rail vehicle etc. The dynamic analysis with stochastic rail parameters (created by Monte Carlo method or by sampling from the real track) will enable to identify the critical states of dynamic interaction in a more actual way. Their result is exceeding the level of safety, comfort or critical degradation of components of rail track and vehicle.

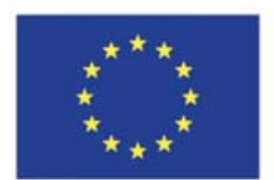

Európska únia

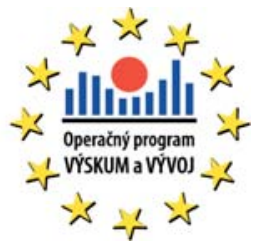

This contribution paper is the result of the project implementation: "Centre of Excellence in Transport Engineering" (ITMS 26220120027) supported by the Research \& Development Operational Programme funded by the ERDF. 


\section{References}

[1] STN 736360 - Geometrical Position and Arrangement of 1435 mm Gauge Railways (in Slovak), SUTN, Bratislava 09/1999, 84 p.

[2] STN P ENV 13803-1 - Railway Applications - Track - Track Alignment Design Parameters - Track Gauges 1435 mm and Wider - Part 1: Plain line (in Slovak), SUTN, Bratislava 08/2004, 82 p.

[3] TNZ 736312 - Designing of Railway Substructure Layers, Railway of Slovak Republic (in Slovak), Bratislava 09/2005, 58 p.

[4] IZVOLT, L.: Railway Substrucutre. Straining, Diagnostics, Designing and Realization of Construction Layers of Railway Subgrade (in Slovak), Zilinská univerzita, Zilina 2008, 324 p., ISBN 978-80-8070-802-3

[5] STN 736190 - Static Plate Load Test of Subgrade and Construction Layers of Roadway (in Slovak). SUTN, Bratislava 9/1980, 14 p.

[6] Predpis ZSR S4 - Railway Subgrade (in Czech), Nakladatelství dopravy a spojů, Praha 1988

[7] MORAVCIK, Mi., MORAVCIK, Ma.: Mechanics of Railway Tracks 1. Theoretical Analysis and Simulation of Railway Tracks' Mechanics (in Slovak), Zilinska univerzita, 2002, 300 p., ISBN 80-7100-983-0

[8] CHOUDHURY, D., BHARTI, K. R., CHAUHAN, S., INDRARATNA, B.: Response of Multilayer Foundation System beneath Railway Track under Cyclic Loading, J. of Geotechnical and Geoenviromental Eng., ASCE, pp. 1558-1563, http://dspace.library.iitb.ac.in/jspui/bitstream/10054/ 1616/1/ASCE5.pdf

[9] SCHUGERL, R.: Dynamic Parameters of Rocks and Processes of their Detection (in Slovak), Acta Geologica Slovaca, Vol. 1, No. 1/2009, pp. 15-26, http://geopaleo.fns.uniba.sk/ageos/archive/ 2009_01/ schugerl_2009.pdf

[10] GERLICI, J., LACK T.: Railway Wheels and Track Interaction (in Slovak), Zilinská univerzita, Zilina 2004, p. 200, ISBN 80-8070$317-5$

[11] MORAVCIK, Mi., MORAVCIK, Ma.: Mechanics of Railway Tracks 2. Theoretical Analysis and Simulation of Railway Tracks' Mechanics (in Slovak), Zilinska univerzita, 2002, 312 p. ISBN 80-7100-984-9

[12] STEFFENS, D. B.: Identification and Development of a Model of Railway Track Dynamic Behaviour, A Thesis Submitted for the Degree of Master of Engineering, Queenland University of Technology, Queenland 2005, 317 p., http://eprints.qut.edu.au/16029/ 1/David_Steffens_Thesis.pdf

[13] LEONG, J.: Development of Limit State Design Methodology for Railway Track, A Thesis Submitted for the Degree of Master of Engineering, Queenland University of Technology, Queenland 2007, 228 p., http://eprints.qut.edu.au/16565/1/ Jeffrey_Leong_Thesis.pdf

[14] ESVELD, C.: Modern Railway Track - Second Edition, Delft University of Technology, Delft 2001, 654 p. ISBN 90-8004-324-3-3

[15] ZAKERI, A. J., XIA, H., FAN, J. J.: Dynamic Responses of Train-track System to Single Rail Irregularity, Latin American J. of Solids and Structures, Vol. 6, No. 2/2009, pp. 89-104, ISSN 1679-7817, http://www.lajss.org/index.php/LAJSS/article/view/ 208/170

[16] TANABE, M., WAKUI, H., MATUMOTO, N.: DIASTARS - Dynamic Interaction Analysis for Shinkansen Train And Railway Structure, http://www.rtri.or.jp/infoce/wcrr97/B595/B595.html

[17] MORAVCIK, Mi., MORAVCIK, Ma.: Mechanics of Railway Tracks 3. Experimental Analysis of Straining and Deformation of Railway Components (in Slovak). Experimentalna analyza namahania a pretvorenia komponentov trate, Zilinska univerzita, Zilina 2002, 220 p. ISBN 80-7100-985-7

[18] IVOLT, L., KARDOS, J., MECAR, M.: Reinforces Subbases and Application of other Chosen Parameters in Sleeper Subgrade Dimensioning. Communications - Scientific Letters of the University of Zilina, No. 3/2007, pp. 21-27, ISSN 1335-4205

[19] IZVOLT, L., KARDOS, J.: Intelligent Compaction Technique as a Tool of Objective and Effective Application of Geosynthetics, Communications - Scientific Letters of the University of Zilina No. 3A/2010, pp. 104-111, 2010, ISBN 80-8070-193-8

[20] MORAVCIK, M.: Dynamics Behavior of Railway Track-experimental Measurements. Communications - Scientific Letters of the University of Zilina, No. 3/2002, pp. 10-16, ISSN 1335-4205

[21] MORAVCIK, M.: Vertical Track Stiffness Effect on Dynamics Behavior of Track Structure. Communications - Scientific Letters of the University of Zilina, No. 3/2004, pp. 45-62, ISSN 1335-4205. 